\title{
Japanese Variant of Multicentric Castleman's Disease Associated With Serositis and Thrombocytopenia - A Report of Two Cases: Is TAFRO Syndrome (Castleman- Kojima Disease) a Distinct Clinicopathological Entity?
}

\author{
Yasufumi Masaki, ${ }^{1)}$ Akio Nakajima, ${ }^{1)}$ Haruka Iwao, ${ }^{1)}$ Nozomu Kurose, ${ }^{2)}$ Tomomi Sato, ${ }^{1)}$ \\ Takuji Nakamura, ${ }^{1)}$ Miyuki Miki, ${ }^{1)}$ Tomoyuki Sakai, ${ }^{1)}$ Takafumi Kawanami, ${ }^{1)}$ \\ Toshioki Sawaki, ${ }^{1)}$ Yoshimasa Fujita, ${ }^{1)}$ Masao Tanaka, ${ }^{1)}$ Toshihiro Fukushima, ${ }^{1)}$ \\ Toshiro Okazaki, ${ }^{1)}$ and Hisanori Umehara ${ }^{1)}$
}

Multicentric Castleman's disease (MCD) is a polyclonal lymphoproliferative disorder that manifests as marked hyper- $\gamma$ globulinemia, severe inflammation, anemia, and thrombocytosis. Recently, Takai et al. reported a new disease concept, TAFRO syndrome, named from thrombocytopenia, anasarca, fever, reticulin fibrosis, and organomegaly. Furthermore, Kojima et al. reported Japanese MCD cases with effusion and thrombocytopenia (Castleman-Kojima disease). Here, we report two cases of MCD associated with marked pleural effusion, ascites, and thrombocytopenia, and discuss the independence of the TAFRO syndrome (Castleman-Kojima disease). Case 1: A 57-year-old woman had fever, anemia, anasarca, and some small cervical lymphadenopathy. Although she had been administered steroid therapy, and full-coverage antibiotics, her general condition, including fever, systemic inflammation, and anasarca, deteriorated steadily. We administered chemotherapy [CHOEP (cyclophosphamide, doxorubicin, vincristine, etoposide, and prednisolone) regimen], but despite a transient improvement, she died due to septic shock. Case 2: A 73-year-old man with a history of aplastic anemia and remission presented with fever, severe inflammation, and anasarca. Prednisolone was administered (15 $\mathrm{mg}$ daily), and his hyperinflammation once improved. Nevertheless, his general condition, including pleural effusion and ascites, worsened, and C-reactive protein and interleukin-6 levels showed marked increases. The patient died due to multiorgan failure. Cases of TAFRO syndrome (Castleman-Kojima disease) are still rare. Therefore, it is necessary to conduct multicenter clinical surveys including similar cases, such as ours, to reach a consensus regarding diagnostic criteria, therapeutic strategy, and pathophysiological etiology for this syndrome. $〔 J C l i n$ Exp Hematop 53(1): 79-85, 2013]

Keywords: Castleman's disease, POEMS syndrome, anasarca, interleukin-6, polyclonal hypergammopathy

\section{INTRODUCTION}

Multicentric Castleman's disease (MCD) is a polyclonal lymphoproliferative disorder (LPD) that manifests as marked hyper- $\gamma$-globulinemia, severe inflammation, anemia, and thrombocytosis. ${ }^{1-4}$ In western countries, this syndrome is

\footnotetext{
Received : December 23, 2012

Revised : January 4, 2013

Accepted : January 7, 2013

${ }^{1)}$ Hematology and Immunology and ${ }^{2)}$ Department of Pathology and Laboratory Medicine, Kanazawa Medical University, Ishikawa, Japan

Corresponding author: Dr. Yasufumi Masaki, Hematology and Immunology, Kanazawa Medical University, Ishikawa 920-0293, Japan

E-mail : yasum@kanazawa-med.ac.jp
}

usually associated with human herpes virus-8 (HHV-8) infection as well as human immunodeficiency virus (HIV) infection. ${ }^{4-6}$ On the other hand, most Japanese patients are negative for both HHV-8 and HIV. Therefore, MCD in western countries and Japan seem to be different disorders. ${ }^{7,8}$ Severe inflammation due to overproduction of interleukin-6 (IL-6) is a finding common to patients in western countries and Japan.

Takai et al. reported a new disease concept, TAFRO syndrome, named from thrombocytopenia, anasarca, fever, reticulin fibrosis, and organomegaly. ${ }^{9}$ Furthermore, Kojima et al. reported Japanese MCD cases with effusion and thrombocytopenia (Castleman-Kojima disease). ${ }^{10}$ These conditions seem to be different from hyaline-vascular type of MCD or 
POEMS syndrome (polyneuropathy, organomegaly, endocrinopathy, $\underline{\mathrm{M}}$ protein, and skin changes).

Here, we report two cases of MCD associated with marked pleural effusion, ascites, and thrombocytopenia, and discuss the independence of the TAFRO syndrome (Castleman-Kojima disease).

\section{Case 1}

A 57-year-old woman with high fever and dry cough was diagnosed with pneumonia anemia (hemoglobin $9.6 \mathrm{~g} / \mathrm{dL}$ ) and thrombocytopenia $\left(52 \times 10^{3} / \mu \mathrm{L}\right)$ one mon before admission to Kanazawa Medical University Hospital (KMU) (Fig. 1). Although antibiotics, antifungal drugs, and $\gamma$-globulin were administered, there were no improvements in her high inflammation, anemia, and thrombocytopenia. Due to suspicion of hemophagocytic syndrome, methylprednisolone pulse therapy (500 $\mathrm{mg} \times 3$ days) followed by prednisolone at $60 \mathrm{mg}$ daily was administered. However, with the exception of dry cough, her condition worsened, and hypoalbuminemia and anasarca (pleural effusion and ascites) emerged and she was admitted to KMU.

The patient gained $14 \mathrm{~kg}$ body weight in one mon. She had fever, anemia, anasarca, and some small cervical lymphadenopathy $(<1 \mathrm{~cm}$ in diameter) on admission to KMU.

On laboratory examination, mild proteinuria and microscopic hematuria were detected by urinalysis. On hematological examination, red blood cell (RBC) count was $2.32 \times$

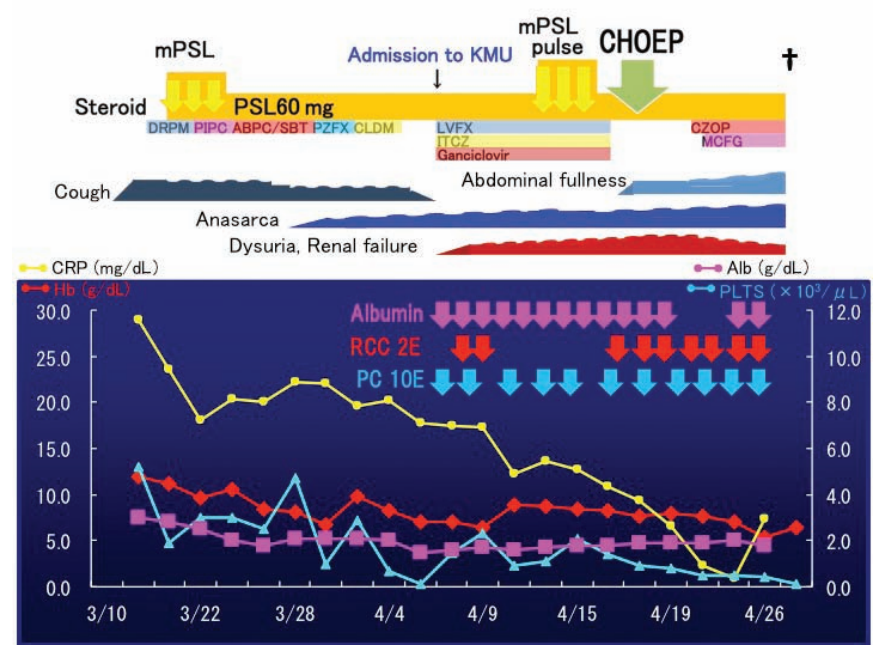

Fig. 1. Clinical course of case 1. mPSL, methylprednisolone; PSL, prednisolone; CHOEP, cyclophosphamide, doxorubicin, vincristine, etoposide, and prednisolone; KMU, Kanazawa Medical University Hospital; DRPM, doripenem; PIPC, piperacillin; ABPC/SBT, ampicillin/sulbactam; PZFX, pazufloxacin; CLDM, clindamycin; LVFX, lomefloxacin; ITXZ, itraconazole; CZOP, cefozopran; MCFG, micafungin RCC, red cell concentrate; PC, platelet concentrate
$10^{6} / \mu \mathrm{L}$, hemoglobin $7.1 \mathrm{~g} / \mathrm{dL}$, hematocrit $20.7 \%$, reticulocytes $11.4 \times 10^{3} / \mu \mathrm{L}$, white blood cell count $6.87 \times 10^{3} / \mu \mathrm{L}$ (neutrophil granulocytes $84.3 \%$, lymphocytes $10.4 \%$, eosinophils $0.8 \%$, and monocytes $1.6 \%$ ), and platelets (PLT) $13 \times 10^{3} / \mu \mathrm{L}$. Erythrocyte sedimentation ratio $(1 \mathrm{hr})$ was elevated to 109 $\mathrm{mm}$, and C-reactive protein (CRP) was elevated $(17.73 \mathrm{mg} /$ $\mathrm{dL}$ ). The patient showed prothrombin time-international normalized ratio 1.44 , activated partial prothromboplastin time $40.6 \mathrm{sec}$, hepaplastin time $34.9 \%$, fibrinogen $461 \mathrm{mg} / \mathrm{dL}$, fibrinogen degradation product $32.1 \mu \mathrm{g} / \mathrm{mL}$, D-dimer 22.85 $\mathrm{mg} / \mathrm{mL}$, and antithrombin III $46.5 \%$. Blood urea nitrogen was $30 \mathrm{mg} / \mathrm{dL}$, creatinine $1.34 \mathrm{mg} / \mathrm{dL}$, total protein $5.0 \mathrm{~g} / \mathrm{dL}$, albumin $1.5 \mathrm{~g} / \mathrm{dL}, \operatorname{IgG} 1,860 \mathrm{mg} / \mathrm{dL}, \operatorname{IgA} 288 \mathrm{mg} / \mathrm{dL}, \operatorname{IgM} 40$ $\mathrm{mg} / \mathrm{dL}$, IgE $97.5 \mathrm{IU} / \mathrm{mL}, \mathrm{C} 375 \mathrm{mg} / \mathrm{dL}, \mathrm{C} 424 \mathrm{mg} / \mathrm{dL}, \mathrm{CH} 50$ $31.1 \mathrm{U} / \mathrm{mL}$, total bilirubin $2.3 \mathrm{mg} / \mathrm{dL}$, direct bilirubin 1.8 $\mathrm{mg} / \mathrm{dL}$, lactate dehydrogenase (LDH) $130 \mathrm{U} / \mathrm{L}$, aspartate aminotransferase $20 \mathrm{U} / \mathrm{L}$, alanine aminotransferase $10 \mathrm{U} / \mathrm{L}$, alkaline phosphatase (ALP) $710 \mathrm{U} / \mathrm{L}$, ferritin $640 \mathrm{ng} / \mathrm{mL}, \beta_{2}$ microglobulin $9.6 \mu \mathrm{g} / \mathrm{mL}$, soluble IL-2 receptor $4,310 \mathrm{U} / \mathrm{mL}$, IL-6 $65.5 \mathrm{pg} / \mathrm{mL}$, and vascular endothelial growth factor (VEGF) $91 \mathrm{pg} / \mathrm{mL}$. Direct and indirect Coombs' tests were both positive $(1+)$, antinuclear antibody $\times 160$ speckled pattern, and platelet-associated IgG $86.7 \mathrm{ng} / 10^{7}$ cells, but other autoantibodies were negative. Serum antibodies against HIV, human T-lymphotropic virus-1, and HHV-8 were all negative. Bone marrow aspiration and biopsy revealed slightly hypercellular bone marrow without any tumor cells, dysplastic changes, hemophagocytosis, or fibrosis. Furthermore, no monoclonality was detected by flow cytometric analysis and no karyotypic abnormalities were detected by G-banding analysis. Massive pleural effusion and ascites were detected by whole-body computed tomography (CT) scan (Fig. 2a), and weak accumulation (standardized uptake value ; SUVmax $<3)$ of ${ }^{18} \mathrm{~F}$-fluorodeoxy glucose $\left({ }^{18} \mathrm{FDG}\right)$ to cervical and abdominal lymph nodes by ${ }^{18} \mathrm{FDG}$-positron emission tomography (PET)-CT (Fig. 2b). On histological examination of cervical lymph node (LND) biopsy specimen, the basic structure of LND was unclear, and massive plasma cell growth around the atrophic germinal center was seen but no neoplastic features were detected (Fig. 3). Therefore, MCD was the most likely diagnosis but lymphadenopathy associated with autoimmune diseases, such as systemic lupus erythematosus, or angioimmunoblastic T-cell lymphoma (AITL) were also considered.

Although she had been administered and continued steroid therapy, including pulse-therapy, and full-coverage antibiotics and antifungal drugs since before and after admission to KMU, the patient's general condition, including fever, systemic inflammation, pancytopenia, and anasarca, deteriorated steadily. Albumin administration and RBC/PLT transfusion did not improve her condition or clinical data. Acute renal failure of pre-renal type occurred, and steroid pulse therapy (methylprednisolone $1 \mathrm{~g} \times 3$ days) was commenced. Al- 

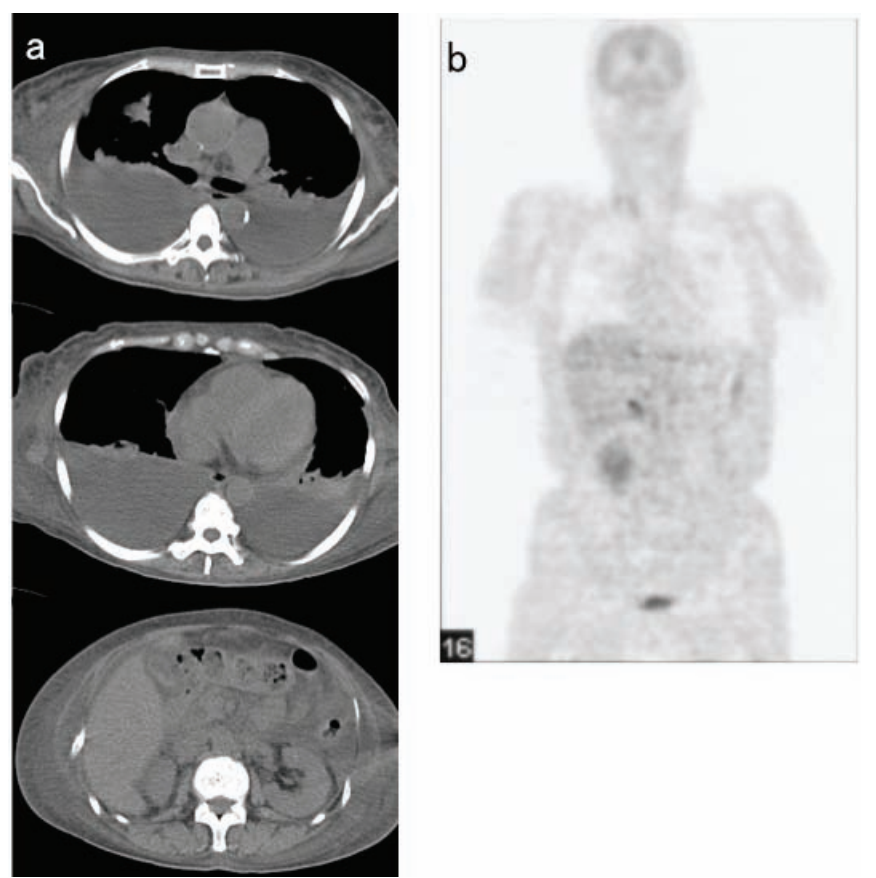

Fig. 2. Imaging study of Case 1. (2a) Whole-body computed tomography scan. $(2 \boldsymbol{b}){ }^{18} \mathrm{~F}$-fluorodeoxy glucose-positron emission tomography $\left({ }^{18}\right.$ FDG-PET). Massive bilateral pleural effusion and ascites were observed on computed tomography scan. Weak accumulation of ${ }^{18} \mathrm{FDG}$ was seen at the right cervical and hepatic portal lymph nodes by ${ }^{18}$ FDG-PET.

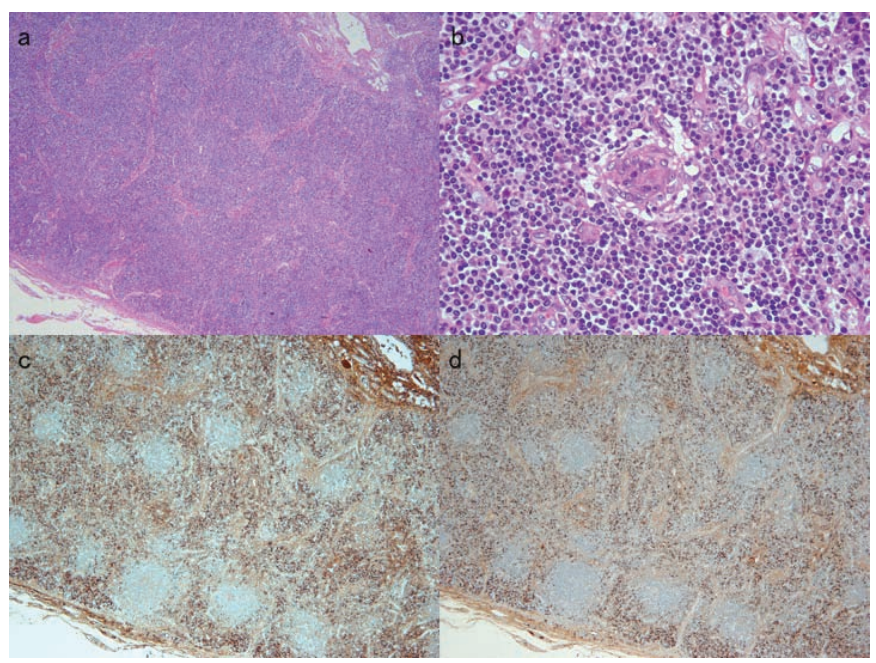

Fig. 3. Cervical lymph node biopsy. (3a) Hematoxylin \& eosin stain, low-power field. (3b) Hematoxylin \& eosin stain, highpower field. (3c) $x$-immunostaining, low-power field. (3d) $\lambda$ immunostaining, low-power field. In cervical lymph node biopsy, multiple lymph nodules, angiogenesis in intrafollicular areas, atrophic germinal center, and massive plasma cell infiltration were observed. No monoclonality was seen. though the result of LND biopsy indicated MCD as the most likely diagnosis, we administered chemotherapy by the CHOEP regimen (cyclophosphamide, doxorubicin, vincristine, etoposide, and prednisolone) because we suspected that she may have lymphoma, especially AITL, due to the progressively deteriorating clinical course. Despite transient improvement of general condition, including renal function, the patient died due to septic shock associated with febrile neutropenia. Bilateral pleural effusion (right $800 \mathrm{~mL}$ and left 700 $\mathrm{mL}$ ) and 3,000 $\mathrm{mL}$ of ascites, splenomegaly (200 g), systemic candida infection were documented, but no particular neoplastic cells were detected at autopsy.

\section{Case 2}

A 73-year-old man with a history of aplastic anemia since the age of 69 years old had been treated with anti-thymocyte globulin, cyclosporin A, granulocyte colony stimulating factor, RBC and PLT transfusion, and anabolic steroid administration (Fig. 4). Due to the efficacy of this treatment, his course of aplastic anemia itself had been become stable with no transfusion requirement since the age of 71 years old, but he had been followed up due to iron overload-induced liver cirrhosis, diabetes mellitus, hypothyroidism, and chronic heart failure. Since September 2008, when he was 72 years old, the patient showed remittent fever, general malaise, CRP elevation, polyclonal hypergammopathy, and hyponatremia. His performance status was grade 3 according to the Eastern Cooperative Oncology Group (ECOG) criteria and he showed marked emaciation. On physical examination, anemia and

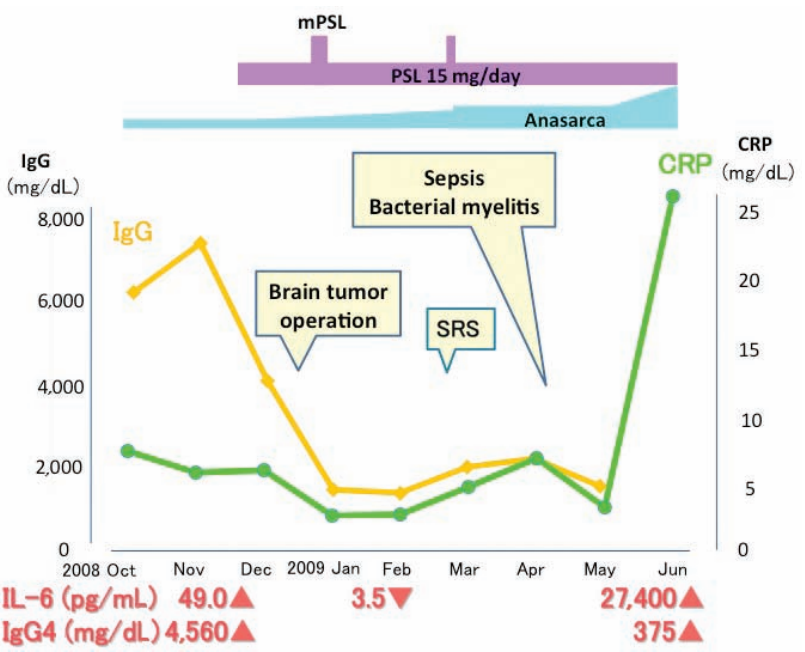

Fig. 4. Clinical course of case 2. Interestingly, at initial presentation of MCD (multicentric Castleman's disease) symptoms, serum IgG4 was elevated as well as serum interleukin-6. However, only marked interleukin-6 was observed at the end stage of the disease course. mPSL, methylprednisolone; PSL, prednisolone; SRS, stereotactic radiosurgery 
horizontal nystagmus toward the left side and clumsiness of bilateral finger-nose test were seen. However, the patient showed neither lymphadenopathy nor hepatosplenomegaly.

Urine test indicated mild proteinuria and microscopic hematuria without casts. On hematological examination, RBC was $1.84 \times 10^{6} / \mu \mathrm{L}$, hemoglobin $7.6 \mathrm{~g} / \mathrm{dL}$, hematocrit $21.5 \%$, reticulocyte $8.6 \times 10^{3} / \mu \mathrm{L}$, white blood cell $4.73 \times$ $10^{3} / \mu \mathrm{L}$ (neutrophil granulocyte $70.0 \%$, lymphocyte $10.5 \%$, eosinophil 15.5\%, and monocyte 3.5\%), and PLT $24 \times$ $10^{3} / \mu \mathrm{L}$. Erythrocyte sedimentation ratio $(1 \mathrm{hr})$ was elevated to $153 \mathrm{~mm}$, and CRP was elevated to $4.17 \mathrm{mg} / \mathrm{dL}$. Prothrombin time-international normalized ratio was 1.25 , activated partial prothromboplastin time $36.7 \mathrm{sec}$, hepaplastin time $59.4 \%$, fibrinogen $243 \mathrm{mg} / \mathrm{dL}$, and D-dimer $1.48 \mathrm{mg} / \mathrm{mL}$. Blood urea nitrogen was $54 \mathrm{mg} / \mathrm{dL}$, creatinine $1.45 \mathrm{mg} / \mathrm{dL}$, sodium $127 \mathrm{mEq} / \mathrm{L}$, potassium $4.7 \mathrm{mEq} / \mathrm{L}$, chlorine $94 \mathrm{mEq} /$ $\mathrm{L}$, total protein $11.1 \mathrm{~g} / \mathrm{dL}$, albumin $1.8 \mathrm{~g} / \mathrm{dL}, \operatorname{IgG} 7,080 \mathrm{mg} / \mathrm{dL}$ (IgG4 4,560 mg/dL), IgA $61 \mathrm{mg} / \mathrm{dL}$, IgM $74 \mathrm{mg} / \mathrm{dL}$, IgE 686 $\mathrm{IU} / \mathrm{mL}, \mathrm{C} 318 \mathrm{mg} / \mathrm{dL}, \mathrm{C} 4<2 \mathrm{mg} / \mathrm{dL}, \mathrm{CH} 5013.0 \mathrm{U} / \mathrm{mL}$, total bilirubin $1.1 \mathrm{mg} / \mathrm{dL}$, LDH $127 \mathrm{U} / \mathrm{L}$, aspartate aminotransferase $57 \mathrm{U} / \mathrm{L}$, alanine aminotransferase $64 \mathrm{U} / \mathrm{L}$, ALP $630 \mathrm{U} / \mathrm{L}$, ferritin $2,217 \mathrm{ng} / \mathrm{mL}, \beta_{2}$-microglobulin $11.4 \mu \mathrm{g} / \mathrm{mL}$, IL-6 49.0 $\mathrm{pg} / \mathrm{mL}$, and VEGF $25 \mathrm{pg} / \mathrm{mL}$. Serum antibodies against HIV, human T-lymphotropic virus-1, and HHV-8 were all negative. Rheumatoid factor was weakly positive $(13 \mathrm{IU} / \mathrm{mL})$, but the patient was negative for all other autoantibodies. Bone marrow aspiration revealed normocellular bone marrow without any tumor cells, dysplastic changes, and hemophagocytosis. Furthermore, no monoclonality was detected by flow cytometric analysis and no karyotypic abnormalities were determined by G-banding analysis. Mild fibrosis was seen in bone marrow biopsy (Fig. 5a \& 5b). CT scan showed bilateral pleural effusion (Fig. 6b) and ascites, but no particular lymphadenopathy or hepatosplenomegaly. Magnetic resonance scan of the brain showed an elliptical mass measuring $2 \times 1$ $\mathrm{cm}$ with high intensity on T2 imaging at the cerebellopontine angle (neurinoma) (Fig. 6a). Weak accumulation of ${ }^{18} \mathrm{FDG}$ in PET-CT was seen on the cerebellopontine angle mass, but no other accumulation, such as lymphadenopathy, was seen (Fig. 6c).

Although no particular mass formation was documented by imaging study, he was suspected to have an MCD-like hyper-IL-6 condition due to severe inflammation and marked polyclonal hyper- $\gamma$-globulinemia.

After admission, prednisolone was administered (15 mg daily), and his hyperinflammation, including CRP, IgG, IgG4, and IL-6, improved once. Open brain surgery was performed for brain tumor (neurinoma) of the cerebellopontine angle followed by stereotactic radiosurgery. Nevertheless, his general condition, including pleural effusion and ascites, worsened and CRP and IL-6 increased markedly. The patient died due to multiple organ failure.

At autopsy, secondary hemochromatosis due to transfu-

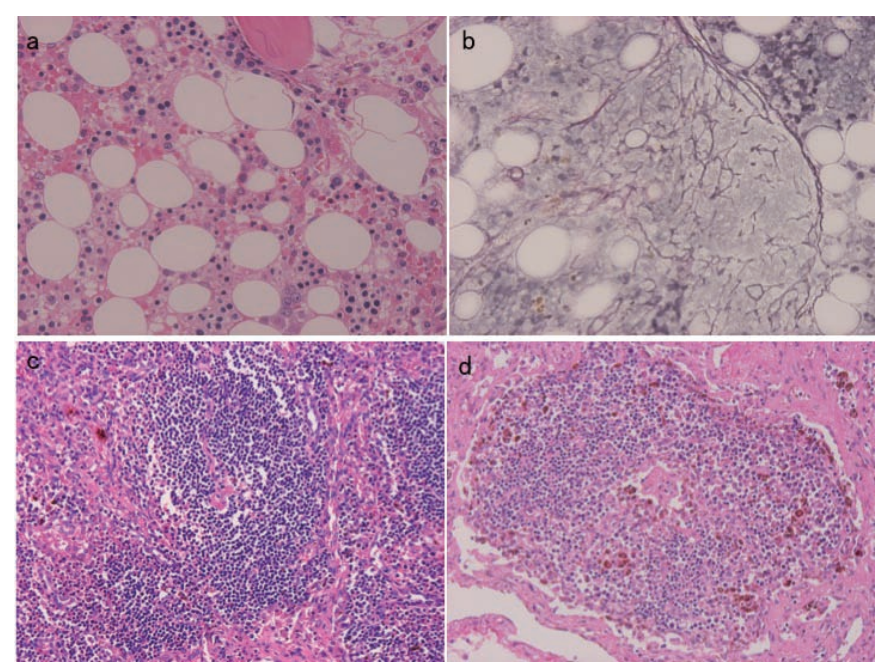

Fig. 5. Bone marrow biopsy of case 2. (5a) Hematoxylin \& eosin stain. (5b) Gitter staining. (5c \& 5d) Autopsy findings of paraaortic lymph node, hematoxylin \& eosin stain. Mild myelofibrosis was observed in bone marrow. Expansion of the mantle zone was seen in lymphatic nodules accompanied by burnt-out germinal centers in lymph nodes. The follicles were penetrated by a sclerotic blood vessel.
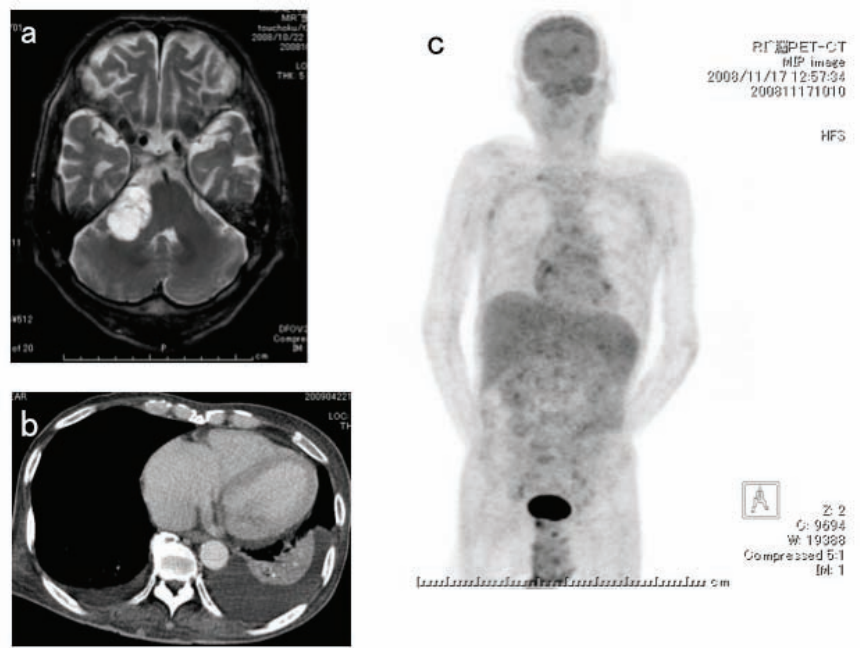

Fig. 6. Imaging study of Case 2. ( $6 \boldsymbol{a}$ ) Brain magnetic resonancecomputed tomography (MR-CT), T2 imaging. ( $6 \boldsymbol{b})$ Chest CT scan. (6c) ${ }^{18} \mathrm{~F}$-fluorodeoxy glucose-positron emission tomography ( ${ }^{18}$ FDG-PET). MR-CT showed an elliptical shaped $2 \times 1 \mathrm{~cm}$ mass showing high intensity on $\mathrm{T} 2$ imaging at cerebellopontine angle (neurinoma). Left side dominant bilateral pleural effusion was observed on chest CT. Weak accumulation of ${ }^{18} \mathrm{FDG}$ was seen in the cerebellopontine angle mass on PET-CT. However, no other areas of accumulation were seen. 
sion, pyogenic spondylitis, small multiple lymphadenopathy showing mixed-type MCD histopathology (HHV-8 negative by immunohistochemical staining) (Fig. $5 \mathrm{c} \& 5 \mathrm{~d}$ ), and massive pleural effusion (right $1,600 \mathrm{~mL}$ and left $1,200 \mathrm{~mL}$ ), 180 $\mathrm{mL}$ of pericardial effusion, $900 \mathrm{~mL}$ of ascites, $160 \mathrm{~g}$ of splenomegaly, and 1,810 $\mathrm{g}$ of hepatomegaly were documented.

\section{DISCUSSION}

Castleman's disease (CD) was first described by Castleman et al. ${ }^{11} \mathrm{CD}$ is a LPD, and three disorders bearing the eponym $\mathrm{CD}$ have been identified and were reviewed by Frizzera et al.: localized CD of the hyaline-vascular (HV) type, localized $\mathrm{CD}$ of the plasma cell (PC) type, and MCD. ${ }^{1-4}$ However, several reports have indicated that MCD is composed of several disease entities, including idiopathic MCD, and secondary MCD due to HIV infection, autoimmune disease-associated lymphadenopathy, POEMS syndrome, and lymphomas. ${ }^{12-19}$ MCD is a clinicopathological entity of generalized LPD that manifests as polyclonal hypergammopathy, anemia, thrombocytosis, and severe inflammation.

The etiology of MCD remains uncertain. MCD in western countries develops in HIV-positive patients associated with HHV-8 and exhibits an aggressive and usually fatal course associated with infectious complications and the development of malignant tumors, such as Kaposi's sarcoma or Bcell lymphoma. ${ }^{4-6}$ Viral IL-6 expression due to HHV-8 infection causes hyper-IL-6 syndrome. Hyper-IL-6 induces VEGF production resulting in vascular synthesis, induces B-cell differentiation resulting in plasma cell expansion and hyper- $\gamma$ globulinemia, induces megakaryocyte differentiation in bone marrow resulting in thrombocytosis, and induces acute inflammatory protein production in the liver resulting in increases in CRP, fibrinogen, serum amyloid A, etc. Furthermore, hepcidin is induced in the liver resulting in microcytic anemia due to both inhibition of iron absorption and a decline of iron recycling from the reticuloendothelial system (Table 1).

On the other hand, MCD in Japan is a hyper-IL-6 syndrome without HIV and HHV-8 infection in most cases, and usually exhibits a chronic disease course. Moreover, MCD in Japan does not appear to progress to Kaposi's sarcoma or Bcell lymphoma.

Kojima et al. reported that idiopathic MCD in Japan consisted of two variants with distinct clinicopathological features, i.e., idiopathic plasmacytic lymphadenopathy with polyclonal hyperimmunoglobulinemia (IPL) ${ }^{20}$ type and non-IPL type. ${ }^{21-24}$ IPL type MCD resembles PC type MCD in western countries characterized by prominent polyclonal hyperimmunoglobulinemia, systemic manifestations, such as malaise, fever, weight loss, and high serum IL-6 levels. ${ }^{1-4}$ Non-IPL type MCD is characterized by mixed type or HV type CD histology, high incidence rate of pleural effusion and ascites, and is frequently associated with autoimmune diseases during the clinical course. Therefore, they suggested that a portion of non-IPL type cases may be secondary MCD, i.e., autoimmune disease-associated LPD. ${ }^{21,24}$

Recently, Takai et al. reported three cases of TAFRO syndrome, a new disease concept that is similar to but is distinct from AITL, PC type MCD, or POEMS syndrome. ${ }^{9}$ Furthermore, Kojima et al. reported seven cases of MCD with effusion at initial clinical presentation, five of which also showed thrombocytopenia (Castleman-Kojima disease). ${ }^{10}$ At a recent meeting, Japanese hematologists and pathologists collaborated to discuss the features of TAFRO syndrome (Castleman-Kojima disease). A number of particular findings were raised at this meeting, such as anasarca (pleural effusion and ascites), thrombocytopenia and microcytic anemia on hemograms, renal dysfunction, ALP elevation, low level of LDH, relatively mild polyclonal hypergammopathy (IgG level is usually $<4,000 \mathrm{mg} / \mathrm{dL}$ ), some immunological abnormalities (positivity of rheumatoid factor, platelet-associated IgG, anti-

Table 1. Possible mechanism of multicentric Castleman's disease (MCD) and Castleman-Kojima disease (TAFRO syndrome)

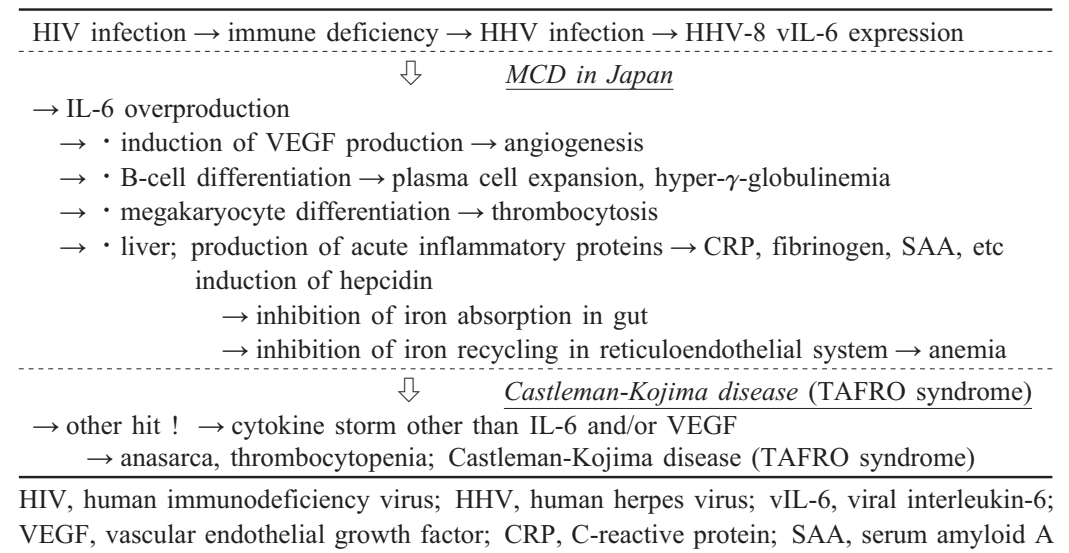


thyroid antibodies, or Coombs' test), elevation of IL-6 and/or VEGF, myelofibrosis, and increased levels of megakaryocytes in bone marrow, small or unclear lymphadenopathy $(>1.5 \mathrm{~cm}$ in diameter) with mild accumulation of ${ }^{18} \mathrm{FDG}$ by ${ }^{18} \mathrm{FDG}-$ PET-CT, and most cases show mixed type, but fewer with HV type of MCD histology. Furthermore, glucocorticoid, immunosuppressive therapy, or tocilizumab may be effective as treatment for patients with this condition.

Our cases did not meet all the criteria for TAFRO syndrome, ${ }^{9}$ but they had the most specific findings, i.e., anasarca (pleural effusion and ascites) and thrombocytopenia, which cannot be explained due only to hyper-IL-6 syndrome. Therefore, they were similar to cases of TAFRO syndrome (Castleman-Kojima disease).

Several questions remain regarding the mechanism and etiology of TAFRO syndrome (Castleman-Kojima disease); is it different from MCD, or some part of $\mathrm{MCD}$, or changes seen in a certain process in MCD (Table 1)? Furthermore, are these conditions neoplastic, autoimmune, infectious, or some other type of disease entities?

Cases of this syndrome are still rare, and it is therefore necessary to conduct multicenter clinical surveys including similar cases such as ours, to reach a consensus regarding diagnostic criteria, therapeutic strategy, and pathophysiological etiology of TAFRO syndrome (Castleman-Kojima disease).

\section{ACKNOWLEDGEMENT}

We thank all participants of the TAFRO syndrome (Castleman-Kojima disease) meeting including for critical discussion.

\section{The sources of support in the form of grants:}

This work was partially supported by the Research Program of Intractable Disease (Research on IgG4-related disease) provided by the Ministry of Health, Labor, and Welfare (MHLW) of Japan, and by the Japanese Ministry of Education, Culture, Sports, Science and Technology (Grant Nos. 13557160, 15024236, 15390313, and 13877075 to Umehara and No. 17591060 to Masaki), the Uehara Memorial Foundation (to Umehara), the Vehicle Racing Commemorative Foundation, the Kanazawa Medical University Research Foundation (Grant Nos. C 2009-4 to Umehara and S 2004-16 and S 2007-5 to Masaki), Grant for Assist KAKEN from Kanazawa Medical University (Grant No. K 2011-7) and Grant for Project Research from High-Tech Research Center of Kanazawa Medical University (Grant No. H 2011-11).

\section{REFERENCES}

1 Frizzera G: Castleman's disease and related disorders. Semin
Diagn Pathol 5:346-364, 1988

2 Frizzera G, Banks PM, Massarelli G, Rosai J: A systemic lymphoproliferative disorder with morphologic features of Castle man's disease. Pathological findings in 15 patients. Am J Surg Pathol 7:211-231, 1983

3 Frizzera G, Peterson BA, Bayrd ED, Goldman A: A systemic lymphoproliferative disorder with morphologic features of Castleman's disease. Clinical findings and clinicopathological correlations in 15 patients. J Clin Oncol 3:1202-1216, 1985

4 Frizzera G: Atypical lymphoproliferative disorders. In: Knowles DM, ed. Neoplastic Hematopathology. 2nd ed. Baltimore, MD: Lippincott Williams \& Wilkins, pp.569-622, 2001

5 Cesarman E, Knowles DM: The role of Kaposi's sarcomaassociated herpesvirus (KSHV/HHV-8) in lymphoproliferative diseases. Semin Cancer Biol 9:165-174, 1999

6 Dupin N, Diss TL, Kellam P, Tulliez M, Du MQ, et al.: HHV-8 is associated with a plasmablastic variant of Castleman disease that is linked to HHV-8-positive plasmablastic lymphoma. Blood 95:1406-1412, 2000

7 Suda T, Katano H, Delsol G, Kakiuchi C, Nakamura T, et al:: HHV-8 infection status of AIDS-unrelated and AIDS-associated multicentric Castlman's disease. Pathol Int 51:671-679, 2001

8 Kojima M, Nakamura N, Tsukamoto N, Otuski Y, Shimizu K, et al:: Clinical implications of idiopathic multicentric Castlman's disease among Japanese. A report of 28 cases. Int J Surg Pathol 16:391-398, 2008

9 Takai K, Nikkuni K, Shibuya H, Hashidate H: Thrombocytopenia with mild bone marrow fibrosis accompanied by fever, pleural effusion, ascites and hepatosplenomegaly. Rinsho Ketsueki 51:320-325, 2010 (in Japanese)

10 Kojima M, Nakamura N, Tsukamoto N, Yokohama A, Itoh H, et al.: Multicentric Castleman's disease representing effusion at initial clinical presentation: clinicopathological study of seven cases. Lupus 20:44-50, 2011

11 Castleman B, Iverson L, Menendez VP: Localized mediastinal lymphnode hyperplasia resembling lymphoma. Cancer 9:822-830, 1956

12 Kojima M, Sakuma H, Mori N: Histopathological features of plasma cell dyscrasia with polyneuropathy and endocrine disturbance with special reference to germinal center lesions. Jpn J Clin Oncol 13:557-576, 1983

13 Tanda F, Massareli G, Constantzi G: Multicentric giant lymph node hyperplasia: an immunohistochemical study. Hum Pathol 14:1053-1058, 1983

14 Nakanishi T, Soube I, Toyokura Y, Nishitani H, Kuroiwa Y, et al.: The Crow-Fukase syndrome. a study of 102 cases in Japan. Neurology 34:712-720, 1984

15 Kessler E: Multicentric giant lymph node hyperplasia. A report of seven cases. Cancer 56:2446-2451, 1985

16 Weisenberger DD, Nathwani BN, Winberg CD, Rappaport H: Multicentric angiofollicular lymph node hyperplasia: a clinicopathologic study of 16 cases. Hum Pathol 16:162-172, 1985

17 Ben-Chetrit E, Flusser D, Okon E, Ackerman Z, Rubinow A: 
Multicentric Castleman's disease associated with rheumatoid arthritis: a possible role of hepatitis B antigen. Ann Rheum Dis 48:326-330, 1989

18 Ioachim HL, Cronin W, Roy M, Maya M: Persistent lymphadenopathies in people at high risk for HIV infection. Clinicopathologic correlations and long-term follow-up in 79 cases. Am J Clin Pathol 93:208-218, 1990

19 Kojima M, Nakamura S, Itoh H, Yoshida K, Asano S, et al:: Systemic lupus erythematosus (SLE) lymphadenopathy presenting with histopathologic features of Castlman's disease: A clinicopathologic study of five cases. Pathol Res Pract 193:565-571, 1997

20 Mori S, Mohri N, Uchida T, Shimamine T: Idiopathic plasmacytic lymphadenopathy with polyclonal hyperimmunoglobulinemia: a syndrome related to giant lymph node hyperplasia of plasma cell type. J Jpn Soc RES 20 (Suppl):55-65, 1980 (in Japanese)

21 Kojima M, Nakamura S, Shimizu K, Itoh H, Yamane Y, et al.:
Clinical implication of idiopathic plasmacytic lymphadenopathy with polyclonal hypergammaglobulinemia. A report of 16 cases. Int J Surg Pathol 12:25-30, 2004

22 Kojima M, Murayama K, Igarashi T, Masawa N, Shimano S, et al.: Bone marrow plasmacytosis in idiopathic plasmacytic lymphadenopathy with polyclonal hyperimmunoglobulinemia. A report of four cases. Pathol Res Pract 203:789-794, 2007

23 Kojima M, Nakamura N, Otuski Y, Itoh H, Ogawa $\mathrm{Y}$, et al.: Pulmonary lesion of idiopathic plasmacytic lymphadenopathy with polyclonal hyperimmunoglobulinemia appears to be a cause of lymphoplasmacytic proliferation of the lung. A report of five cases. Pathol Res Pract 204:185-190, 2008

24 Kojima M, Nakamura N, Tsukamoto N, Otuski Y, Shimizu K, et al.: Clinical implications of idiopathic multicentric Castleman disease among Japanese: a report of 28 cases. Int J Surg Pathol $16: 391-398,2008$ 